\title{
Cultural, Chemical, and Alternative Control Strategies for Rhizopus Soft Rot of Sweetpotato
}

\author{
A. C. Scruggs, Graduate Research Assistant, and L. M. Quesada-Ocampo, Assistant Professor, Department of Plant Pathology, North Car-
} olina State University, Raleigh 27695

\begin{abstract}
Scruggs, A. C., and Quesada-Ocampo, L. M. 2016. Cultural, chemical, and alternative control strategies for Rhizopus soft rot of sweetpotato. Plant Dis. 100:1532-1540.

Rhizopus soft rot, caused primarily by Rhizopus stolonifer, is one of the most common postharvest diseases of sweetpotato and is often considered the most devastating. Traditionally, Rhizopus soft rot has been effectively controlled using postharvest dips in dicloran fungicides; however, due to changes in market preferences, use of these fungicides is now limited. This, along with the lack of labeled and effective fungicides for control of Rhizopus soft rot in sweetpotato, creates the need for integrated strategies to control the disease. The effects of storage temperature $\left(13,23\right.$, and $\left.29^{\circ} \mathrm{C}\right)$, relative humidity $(80,90$, and $100 \%)$, and initial inoculum levels (3-, 5-, and 7-mm-diameter mycelial plugs) on progression of Rhizopus soft rot in 'Covington' sweetpotato were examined. Percent decay due to Rhizopus soft rot infection was significantly reduced $(P<0.0001)$ at a low temperature $\left(13^{\circ} \mathrm{C}\right)$ but was not significantly affected by changes in relative

humidity or initial inoculum level $(P>0.05)$. Sporulation of $R$. stolonifer was also significantly reduced at the lowest temperature of $13^{\circ} \mathrm{C}$. High relative humidity ( $>95 \%$ ) significantly increased sporulation of $R$. stolonifer and sporulation also increased as initial inoculum level increased. Efficacy of chlorine dioxide $\left(\mathrm{ClO}_{2}\right)$ fumigation, UV-C irradiation, and postharvest dips in alternative control products were also investigated for control of Rhizopus soft rot. Static $\mathrm{ClO}_{2}$ treatments were effective in reducing sporulation on treated roots but had no significant impact on incidence of Rhizopus soft rot. UV irradiation at $3.24 \mathrm{KJ} / \mathrm{m}^{2} 1 \mathrm{~h}$ after inoculation as well as dips in aqueous $\mathrm{ClO}_{2}$ and StorOx 2.0 significantly $(P<0.05)$ reduced disease incidence. Understanding the epidemiological factors favoring Rhizopus soft rot and identifying alternative control strategies allow for improved recommendations to limit postharvest losses in sweetpotato.
\end{abstract}

Sweetpotato is an important crop worldwide, with total production of sweetpotato ranking seventh among all crops (FAOSTAT 2009). Sweetpotato is particularly important in many developing countries, where the tubers are relied on heavily as a source of food or income for small farmers. Orange-fleshed sweetpotato is very high in vitamin A and other essential nutrients (Woolfe 1992), and crops are being used to combat nutritional disorders in many developing countries throughout Africa and Asia. Sweetpotato vines and roots are commonly used as livestock feed in many countries (Scott 1992) and misshapen or discarded roots are increasingly being used for pet food in the United States (Bickers 2015). A recent increase in U.S. sweetpotato consumption shows the growing importance of this crop across the nation, due primarily to value-added products such as sweetpotato fries and chips (Johnson et al. 2015). North Carolina is the leading producer of sweetpotato in the United States and is responsible for about $50 \%$ of the nation's production, which is valued at over $\$ 260$ million in farm gate value for North Carolina (NCDA and CS 2015).

After harvest, sweetpotato tubers are often stored for up to 1 year to ensure year-round market supply for consumers. During this time, losses may occur due to factors that include chill injury, cracking, pithiness, insect injury, and disease occurrence (Edmunds et al. 2008). Although sweetpotato roots are affected by several plant pathogens, Rhizopus soft rot is often considered the most devastating postharvest disease of sweetpotato, resulting in an estimated $2 \%$ loss in storage roots before they reach retail market (Ceponis and Butterfield 1974; Clark and Moyer 1988). Rhizopus soft rot occurs most often on wounded sweetpotato roots that were injured by harvesting tools, insects, washing equipment, and so on, because injury is necessary for infection. It has been shown; however, that type of wounding and storage time can affect the sweetpotato's susceptibility to Rhizopus stolonifer. In a 2-year study by Holmes and Stange (2002), it was

Corresponding author: L. M. Quesada-Ocampo; E-mail: Imquesad@ncsu.edu Accepted for publication 25 March 2016.

http://dx.doi.org/10.1094/PDIS-01-16-0051-RE

(C) 2016 The American Phytopathological Society found that, among bruising, breaking, scraping, and puncturing, bruising was most conducive for Rhizopus soft rot development. Wounds that are more likely to crush the plant tissue are generally more susceptible to infection by Rhizopus spp. because they release more nutrients that can be used to support fungal growth (Holmes and Stange 2002). Disease occurrence appeared most often from 100 to 175 days after harvest, because susceptibility declined following this time period (Holmes and Stange 2002). Curing of sweetpotato tubers in higher temperatures and humidity reduces the chance of infection, due to suberization of the wounded areas of the sweetpotato, thus minimizing the area for infection to occur (Artschwager and Starrett 1931). However, unclean washing and packing facilities as well as improper storage can increase the risk of Rhizopus infection.

Rhizopus spores are continually in the air, and can survive easily on crop debris, fruits and vegetables themselves, and tools and equipment. When a fungal spore comes in contact with a wound on the sweetpotato, the spore germinates and sends fungal hyphae into the tissue (Nelson 2009). Rhizopus spp. have been shown to produce numerous enzymes, including amylase, pectinase, and cellulase that damage cell walls and permit host colonization (Ogundero 1988; Tang et al. 2012). Upon initial infection, a soft lesion forms around the inoculation point and the disease quickly spreads throughout the entire root, resulting in a soft, watery, and stringy sweetpotato in as little as 3 days. Infection generally occurs around a wounded area but may also begin from the end of the root where the sweetpotato is connected to the vine. The enzymes exuded from the pathogen generally liquefy the internal parenchyma of the root, leaving the periderm and outer fibers of the root intact. A characteristic feature of Rhizopus soft rot that can aid in differentiating it from other postharvest rots is the "whiskers" that arise from the periderm occasionally around the root (Clark et al. 2013). These whiskers are tufts of hyphae containing numerous sporangia and generally appear around lenticels or breaks in the periderm. Sometimes hyphae may not be visible on the outside of the root but can be viewed by pulling apart the infected tissue, giving it a stringy appearance (Clark et al. 2013). Avoidance of Rhizopus spp. is difficult due to their ubiquitous nature; therefore, sanitation and storing sweetpotato under unfavorable disease conditions is key to control this pathogen. To date; however, it is unclear how storage conditions may affect progression of Rhizopus soft 
rot and understanding this epidemiology may allow for improved control of the disease.

Resistance to Rhizopus soft rot in sweetpotato has been a goal of breeding programs but no definite resistance has been achieved. Variety trials have shown some cultivars to be less susceptible than others, with Beauregard showing the most resistance to date (Clark et al. 2009). Traditionally, control of this disease has relied on postharvest dips in dicloran fungicides such as Botran. However, due to tighter residue restrictions in European markets and changes in consumer preferences, use of these fungicides is now limited, creating the need for additional control options and integrated control strategies. Therefore, the purpose of this study was to identify temperatures (13, 23 , and $29^{\circ} \mathrm{C}$ ), relative humidity levels $(80,90$, and $100 \%)$, and initial inoculum levels (3-, 5-, and 7-mm mycelia plugs) that promote Rhizopus soft rot in sweetpotato, to compare the efficacy of fungicides and organic products in controlling the disease, and to evaluate alternative control options such as UV-C irradiation and fumigation with chlorine dioxide $\left(\mathrm{ClO}_{2}\right)$ gas. With this information, novel and integrated strategies can be developed to reduce postharvest losses in sweetpotato to Rhizopus soft rot.

\section{Materials and Methods}

Host and pathogen material. At the time of inoculation for each experiment, 'Covington' sweetpotato roots were obtained from a single commercial sweetpotato farm. Covington was selected due to its large-scale production in North Carolina. All roots used in this study had been previously cured at industry standards (Edmunds et al. 2008) and were selected based upon consistent size, shape, and a disease-free appearance. Prior to inoculation for the epidemiological experiments, sweetpotato roots were surface sterilized by soaking them in 5\% sodium hypochlorite for 5 min, individually rinsing them with sterile water, and placing them into a laminar flow hood to air dry. Sweetpotato roots used for fungicide dips and alternative control experiments were only rinsed in water and were not surface sterilized prior to inoculation.

An actively growing culture of $R$. stolonifer isolate AS046 was used for inoculation in each epidemiology experiment, the active $\mathrm{ClO}_{2}$ fumigation tests, and the fungicide dips. Isolates AS046 and AS511 were used to create a spore suspension used in inoculation of the UV treatments and the static $\mathrm{ClO}_{2}$ treatments. Isolate ASO46 was collected from an infected sweetpotato sample submitted to the North Carolina State Plant Disease and Insect Clinic and isolate AS511 was also collected from an infected root sweetpotato at a commercial packing facility in North Carolina. Both isolates were hypha-tipped to ensure pure cultures. DNA extraction followed by amplification of the internal transcribed spacer (ITS) region using primers ITS4 and ITS1 (White et al. 1990) were performed and polymerase chain reaction (PCR) products were sequenced to molecularly characterize the isolate. A BLAST search of the produced sequence from AS046 revealed a 100\% identity to an $R$. stolonifer isolate (GenBank accession number HM212636), and the AS511 sequence had a $99 \%$ identity to a Rhizopus sp. isolate (accession number KJ619384). The AS046 sequence also matched $R$. oryzae; therefore, both isolates were further confirmed as $R$. stolonifer by their ability to grow at $30^{\circ} \mathrm{C}$ but not at $40^{\circ} \mathrm{C}$ (Liou et al. 2007). ITS sequences of isolates AS046 and AS511 have been submitted to GenBank under accession numbers KU507201 and KU507200, respectively. Cultures were maintained on potato dextrose agar (PDA) and stored at $4{ }^{\circ} \mathrm{C}$. Isolates were transferred onto fresh PDA media 7 days before inoculation and kept under light at $23^{\circ} \mathrm{C}$.

Wounding and inoculations for epidemiology experiments. Upon drying, sweetpotato roots were placed into a plastic box one at a time. Prior studies indicate that bruising is the most conducive wound type for disease development (Holmes and Stange 2002). Therefore, in order to bruise roots, a 589-g metal rod with a diameter of $10 \mathrm{~mm}$, sterilized with $80 \%$ ethanol, was dropped through a 3/4-in. PVC pipe, to ensure accuracy, onto the middle of the sweetpotato from a height of $45 \mathrm{~cm}$, thus eliciting an average impact force of 866 Newtons. A consistent bruising wound approximately 3 to $5 \mathrm{~mm}$ deep and $10 \mathrm{~mm}$ in diameter was inflicted on the roots. Roots were immediately placed individually with the wounded side up into sterile, clear plastic containers ( 28 by 20 by $14 \mathrm{~cm}$ ).

Sweetpotato roots were inoculated using mycelium plugs $(5 \mathrm{~mm}$ in diameter) from 7-day-old cultures for all experiments, except for the inoculum level experiment, where 3- and 7-mm-diameter plugs were used as treatments. Plugs were taken along the outer edge of cultures to ensure that the same amount and type of inoculum was contained in each plug. Plugs were placed face down onto the edge of the wounded area of the root, ensuring that the fungus contacted the pith tissue. Control roots were wounded but not inoculated.

Effects of temperature on disease development. Three sterile paper towels were moistened with approximately $15 \mathrm{ml}$ of sterile water and placed in the plastic containers alongside the sweetpotato to maintain high humidity (approximately 100\%). Six inoculated roots and six control roots in individual containers were each placed into a growth chamber set at either 13,23 , or $29^{\circ} \mathrm{C}$. Temperatures of 13,23 , and $29^{\circ} \mathrm{C}$ were chosen for study because they represent the current recommended temperature for long-term storage, standard room temperature, and the curing temperature, respectively. This experiment was conducted two times. Roots were evaluated every day for 11 days for sporulation area and percent decay. Sporulation area was calculated by measuring the diameter of visible fungal growth around the inoculation site. Area under the disease progress curve (AUDPC) values were calculated for each variable per root. Data residuals were calculated, checked for normality using the Shapiro-Wilk normality test, quantile-quantile (Q-Q) plots, and boxplots, and checked for equality of variances using Levene's test using $\mathrm{R}$ ( $\mathrm{R}$ Core Team 2013). Once residuals were found to follow statistical assumptions, the data were subjected to analysis of variance (ANOVA). Effects were considered significant at 0.05 and means separated using Tukey's test.

Effect of humidity on disease development. Relative humidity levels targeted at 80,90, and $100 \%$ were tested for their effect on disease progression in the individual containers. Actual mean relative humidities observed in the incubation chambers during the course of the experiment were $80.9,89.1$, and $95.2 \%$, respectively, but 80 , 90 , and $100 \%$ were still used in the following sections for easy expression. Preliminary experiments were performed to consistently achieve the desired humidity levels by adding specific volumes of water inside the container. The method was standardized at $23^{\circ} \mathrm{C}$ and took into account the humidity derived from the normal respiration of an uninfected root by placing a sweetpotato in the container during preliminary experiments. An $80 \%$ humidity was achieved by placing a sweetpotato alone into the chamber, while $90 \%$ humidity required the addition of $10 \mathrm{ml}$ of sterile water in a $60-\mathrm{mm}$ petri dish, and $100 \%$ humidity required the addition of three sterile paper towels dampened with $15 \mathrm{ml}$ of sterile water. Sets of six inoculated roots and six control roots maintained at either 80,90 , or $100 \%$ relative humidity were placed into separate growth chambers set at $23^{\circ} \mathrm{C}$. Roots in each growth chamber were incubated for 11 days in the dark, and Watchdog model B102 data loggers (Spectrum Technologies, Plainfield, IL) were placed randomly in each treatment to monitor the relative humidity throughout the duration of the experiment. This experiment was conducted two times and disease evaluation and data analysis were performed as described for temperature experiments.

Effect of inoculum level on disease development. Three sterile paper towels were moistened with approximately $15 \mathrm{ml}$ of sterile water and placed in the plastic chambers alongside the sweetpotato to maintain high humidity (approximately 100\%). Sets of six roots inoculated with either 3-, 5-, or 7-mm-diameter mycelia plugs and six control roots were placed into a growth chamber set at $23^{\circ} \mathrm{C}$. These roots were incubated for 11 days in the dark. This experiment was conducted two times and disease evaluation and data analysis were performed as described for temperature experiments.

UV-C irradiation experiment. UV treatment was conducted in a 1300 Series A2 Biosafety Cabinet (Thermo Scientific, Waltham, MA) using the factory-installed UV lamp, emitting UV radiation at $254 \mathrm{~nm}$. A UVC Light Meter 850010 (Sper Scientific, Scottsdale, $\mathrm{AZ}$ ) was used to measure the UV-C dose rates. The average dose rate over the entire treatment surface was $0.12 \mathrm{~mW} / \mathrm{cm}^{2}$. The exposure 
times for different treatments were 15,45 , and $105 \mathrm{~min}$. UV doses were calculated based upon the measured dose rate and the exposure time using the formula Dose $\left(\mathrm{mJ} / \mathrm{m}^{2}\right)=$ exposure time (seconds) $\times$ dose rate $\left(0.12 \mathrm{~mW} / \mathrm{cm}^{2}\right)$, modified from Stevens et al. (1999), yielding doses of $1.08,3.24$, and $7.56 \mathrm{KJ} / \mathrm{m}^{2}$, respectively.

To investigate induced resistance from UV-C hormesis, 30 roots were randomly selected, assigned a number, and placed into the biosafety cabinet for treatment. Roots were then exposed to UV treatment and, after $15 \mathrm{~min}, 10$ roots were selected using a random number generator and removed from treatment after receiving a dose of $1.08 \mathrm{KJ} / \mathrm{m}^{2}$. The UV treatment was then continued for an additional $30 \mathrm{~min}$. After this time, another 10 roots were randomly selected and removed after receiving a dose of $3.24 \mathrm{KJ} / \mathrm{m}^{2}$. The remaining roots were exposed to an additional $60 \mathrm{~min}$ of treatment, receiving a dose of $7.56 \mathrm{KJ} / \mathrm{m}^{2}$. Following treatment, roots were stored in sealed, clear plastic boxes ( 40 by 50 by $17.9 \mathrm{~cm}$ ) in the dark at $23^{\circ} \mathrm{C}$. After $24 \mathrm{~h}$, roots were wounded twice on opposing sides, perpendicular to the surface contacting the bench, using a rubberband-propelled wooden dowel (Holmes and Stange 2002), inflicting a bruise-type wound $8 \mathrm{~mm}$ in diameter and $2 \mathrm{~mm}$ deep. Roots were then inoculated by dipping into an $R$. stolonifer spore suspension for $30 \mathrm{~s}$. The spore suspension was generated by cutting up 7-day-old cultures of isolates AS046 and AS511 into 10-mm squares and suspending them in sterile water at a rate of one plate of each isolate per liter of water to generate a spore suspension concentration of approximately $10^{6}$ spores $/ \mathrm{ml}$. After air drying for $1 \mathrm{~h}$, roots were placed by treatment back into the sealed, clear plastic boxes containing five dampened paper cloths to maintain high humidity. Inoculated, untreated controls and wounded, uninoculated controls were included, and roots were stored at $23^{\circ} \mathrm{C}$. At 10 days postinoculation (dpi), roots were rated for disease incidence.

To determine whether UV treatment could have a curative effect, 30 roots were wounded and inoculated as described in the above UV experiment. One hour after inoculation, roots were randomly assigned treatments and treated at the same doses used above. Treatment and storage were consistent with the procedure described above. Each experiment was conducted three times. Percent disease incidence data across all treatment levels were analyzed in R (R Core Team 2013) using Pearson's $\chi^{2}$ test. A posthoc $\chi^{2}$ analysis was used for separation between treatment levels. $P$ values were adjusted using the false discovery rate method and considered significant at 0.05 .

$\mathrm{ClO}_{2}$ fumigation. $\mathrm{ClO}_{2}$ gas was produced using a system developed by ICA TriNova Corporation (Newnan, GA). Dry granules (10 g) of a sodium chlorite compound were mixed with $10 \mathrm{~g}$ of a proprietary acid activator in a Tyvek sachet to produce a known quantity of $\mathrm{ClO}_{2}$ via an acidic disproportionation process (Table 1). Upon mixing, the gas would freely diffuse through the sachet into the treatment container. For the purposes of the present study, varying numbers of sachets were used to generate low and high rates of $\mathrm{ClO}_{2}$ as treatments (Table 1). Two methods of application were also tested: a static treatment and a circulatory system (active) treatment that used a fan to deliver $\mathrm{ClO}_{2}$ gas through a column of inoculated roots (Fig. 1).

For the static treatment, 30 roots were wounded and inoculated as described above for the UV tests. Roots were divided into sets of 10 and were placed into sealed, clear plastic containers ( 40 by 50 by $17.9 \mathrm{~cm}$ ) along with five dampened paper cloths to maintain high

Table 1. Quantity of chlorine dioxide $\left(\mathrm{ClO}_{2}\right)$ produced during each treatment level for both gas delivery systems based on the amount of activated product used and exposure time

\begin{tabular}{lcc}
\hline Treatment & $\begin{array}{c}\text { Number of 10-g } \\
\text { sachets }\end{array}$ & $\begin{array}{c}\text { Approximate ClO } \\
\text { quantity }(\mathbf{m g})\end{array}$ \\
\hline Static & 1 & 90 \\
Low & 3 & 270 \\
High & & \\
Active & 3 & 240 \\
Low & 6 & 480 \\
High & & \\
\hline
\end{tabular}

humidity. Ten roots received a low rate of $\mathrm{ClO}_{2}$ gas produced by the addition of one activated sachet to the container. Another 10 roots received a high rate of $\mathrm{ClO}_{2}$, generated by the addition of three activated sachets to the storage container. Because $\mathrm{ClO}_{2}$ gas is heavier than air, the sachets were taped to the inside of the lid of the plastic container for both treatments to allow the gas to settle down on the roots. In all, 10 roots were inoculated and untreated for positive controls and another 10 roots were wounded but not inoculated for negative controls. Roots were evaluated individually for sporulation area and overall for disease incidence $10 \mathrm{dpi}$. The experiment was conducted three times. Data analysis for disease incidence was conducted as described above for the UV experiments. Sporulation area of each root was individually determined using image analysis through the program ImageJ (Schneider et al. 2012). The proportion of each root that was covered in growth of $R$. stolonifer was calculated and subject to an ANOVA. Effects were considered significant at 0.05 and means separated using Tukey's test.

The circulatory system consisted of four 18.9-liter chambers with numerous $10-\mathrm{mm}$ holes drilled in the bottom, each sitting in an additional chamber of equal size. Twenty-five sweetpotato roots were placed into each chamber on top with holes in the bottom, to create a column of roots that the gas could pass in and out of (Fig. 1). Smaller, 1.9-liter containers were attached to each bucket. Treatment sachets were placed into these containers for the columns receiving treatment. Air was generated using a Koala Blower model KP1200 (B-Air Blowers, Azusa, CA) (Fig. 1). Air was pumped into a 7.6-cm PVC pipe that was then reduced to $2.5 \mathrm{~cm}$ before entering through the lid in the small, side container. Another 2.5-cm PVC pipe connected the bottom of the side container to the bottom of the chamber that held the top chamber, which contained the roots (Fig. 1). This forced $\mathrm{ClO}_{2}$ generated by the sachets into the chambers containing sweetpotato, through the column of roots, and then out through a valve in the lid of the bucket containing roots (Fig. 1). Twenty-five roots received a low rate of $\mathrm{ClO}_{2}$ gas produced by the addition of three activated sachets to the small container. Another 25 roots received a high rate of $\mathrm{ClO}_{2}$, generated by the addition of six activated sachets to the storage container. The number of sachets differed from the static treatments due to the higher number of roots being treated. Roots were treated for a period of $4 \mathrm{~h}$, then removed from the treatment chambers and placed into a sealed, clear plastic container ( 40 by 50 by $17.9 \mathrm{~cm}$ ) along with five dampened paper clothes to maintain high humidity. Roots were stored in the dark at $23^{\circ} \mathrm{C}$. A third container contained 25 inoculated roots that received no treatment and a fourth container held 25 roots that were wounded but not inoculated. Roots were treated for a period of $4 \mathrm{~h}$ and then removed and placed by treatment into a sealed, clear plastic container along with five dampened paper

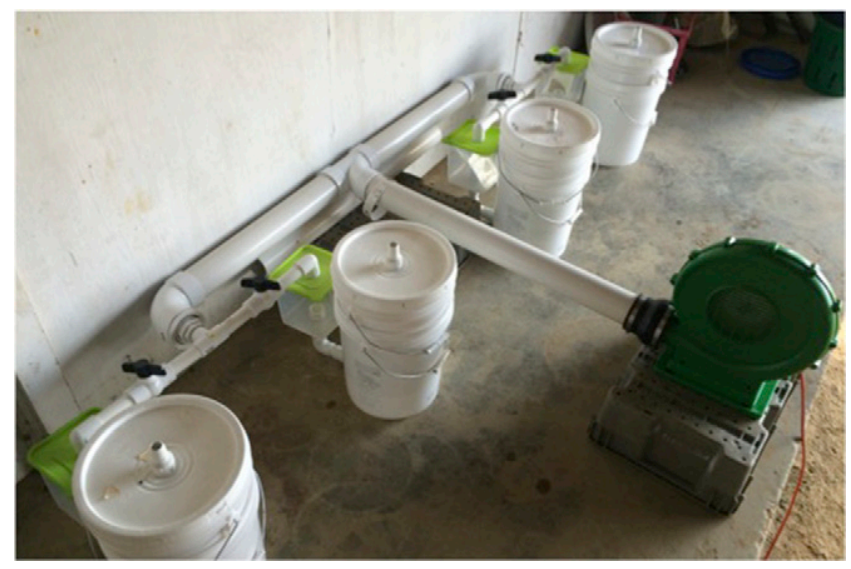

Fig. 1. Active, circulating chlorine dioxide $\left(\mathrm{ClO}_{2}\right)$ system designed to simulate treatment of roots inside of a commercial storage room. Roots were placed in the top white 5-gal. bucket that had numerous 10-mm holes drilled in the bottom. Activated gas sachets were placed in the clear, side containers with green lids. Air generated by the fan pushes $\mathrm{ClO}_{2}$ gas produced by the activated sachets into the bottom of a white 5-gal. bucket, through the column of inoculated roots, and then out of the tube on top of the 5-gal. bucket. 
clothes to maintain high humidity. Roots were stored in the dark at $23^{\circ} \mathrm{C}$ and evaluated after 10 days individually for percent decay and overall for disease incidence. The experiment was conducted twice and data analysis for disease incidence was performed as described above.

Alternative product dips. Roots were wounded using the rubberband-propelled wooden dowel and inoculated with a 5-mm mycelia plug. After inoculation, roots were incubated in sealed, clear plastic containers ( 40 by 50 by $17.9 \mathrm{~cm}$ ) at $23^{\circ} \mathrm{C}$ and $95 \%$ relative humidity for $24 \mathrm{~h}$ before treatment. Roots were then dipped into a given treatment (Table 2) for $30 \mathrm{~s}$. Inoculated, untreated controls and uninoculated controls were included. Following treatment, roots were placed back into their container and stored in the dark at $23^{\circ} \mathrm{C}$ and $95 \%$ relative humidity. Ten roots were used per treatment and the experiment was conducted three times. Roots were evaluated 10 days after treatment for disease incidence and data analysis was performed as described above for disease incidence.

\section{Results}

Effect of temperature on disease development. Symptoms consistent with Rhizopus soft rot (Clark et al. 2013) were observed across all storage treatments (Fig. 2). Initial symptoms were a soft lesion at the point of inoculation which, under favorable conditions, quickly spread to the entire root, resulting in a soft, watery sweetpotato. Gray mycelia

Table 2. Products tested for efficacy against Rhizopus soft rot of sweetpotato and the tested application rate

\begin{tabular}{llc}
\hline Active ingredients & \multicolumn{1}{c}{ Product } & Tested rate \\
\hline Dicloran & Botran 75WP & $1.2 \mathrm{~g} / \mathrm{liter}$ \\
Rhamnolipid biosurfactant & Zonix & $6.25 \mathrm{ml} / \mathrm{liter}$ \\
Hydrogen peroxide, peroxyacetic acid & StorOx 2.0 & $20.0 \mathrm{ml} / \mathrm{liter}$ \\
Potassium phosphite & Prophyt & $5.0 \mathrm{ml} / \mathrm{liter}$ \\
$\mathrm{ClO}_{2}$ & Z-series & $5 \mathrm{ppm}$ \\
\hline
\end{tabular}

giving rise to black sporangia were abundant at the site of inoculation under favorable conditions. Disease progression (AUDPC) calculated using estimated percent decay over an 11-day period significantly increased as temperature increased for the tested temperature levels (Table 3). Storage at $13^{\circ} \mathrm{C}$ provided the highest level of control for Rhizopus soft rot while storage at $29^{\circ} \mathrm{C}$ resulted in the highest loss (Table 3). Symptoms of Rhizopus soft rot were apparent 1 dpi for storage at 23 and $29^{\circ} \mathrm{C}$; however, initial symptoms were delayed until 4 dpi for roots stored at $13^{\circ} \mathrm{C}$ (Fig. 3A). Furthermore, storage at higher temperatures $\left(29^{\circ} \mathrm{C}\right)$ resulted in a faster rate of decay than lower temperatures, with almost all roots being $100 \%$ decayed by $7 \mathrm{dpi}$ (Fig. 3A). Storage at $13^{\circ} \mathrm{C}$ both increased the time until initial symptom development and reduced the rate of decay. No roots were $100 \%$ decayed after $11 \mathrm{dpi}$ when stored at $13^{\circ} \mathrm{C}$ (Fig. 3A). Sporulation of $R$. stolonifer, measured by the diameter of the sporulating area, was also significantly affected by storage temperature: sporulation in storage at $13^{\circ} \mathrm{C}$ was less than that at 23 and $29^{\circ} \mathrm{C}$ (Table 3). Sporulation of R. stolonifer was apparent on infected roots after $1 \mathrm{dpi}$ when stored at 23 and $29^{\circ} \mathrm{C}$; however, sporulation was delayed at $13^{\circ} \mathrm{C}$ until $3 \mathrm{dpi}$ (Fig. 3B). Sporulation also increased at a faster rate at the higher temperatures compared with $13^{\circ} \mathrm{C}$. Storage at $13^{\circ} \mathrm{C}$ increased the time until sporulation began and reduced the amount of sporulation over the 11-day observation period (Fig. 3B)

Effect of humidity on disease development. AUDPC values calculated over an 11-day period for varying relative humidity levels $(80,90$, and $100 \%)$ revealed no significant difference between storage humidities for disease progression using estimated percent decay (Table 3). For each tested humidity level, symptoms were first observed at $2 \mathrm{dpi}$ (Fig. 3C). Disease progressed at a similar rate between each of the tested levels. All roots stored at $100 \%$ humidity were $100 \%$ decayed by 7 dpi, whereas roots stored at either 80 or $90 \%$ humidity were never all $100 \%$ decayed (Fig. 3C). This difference, however, was not significant (Table 3). Relative humidity levels tested had no effect on percent decay but did have a significant effect on sporulation (Table 3). No difference in sporulation was observed
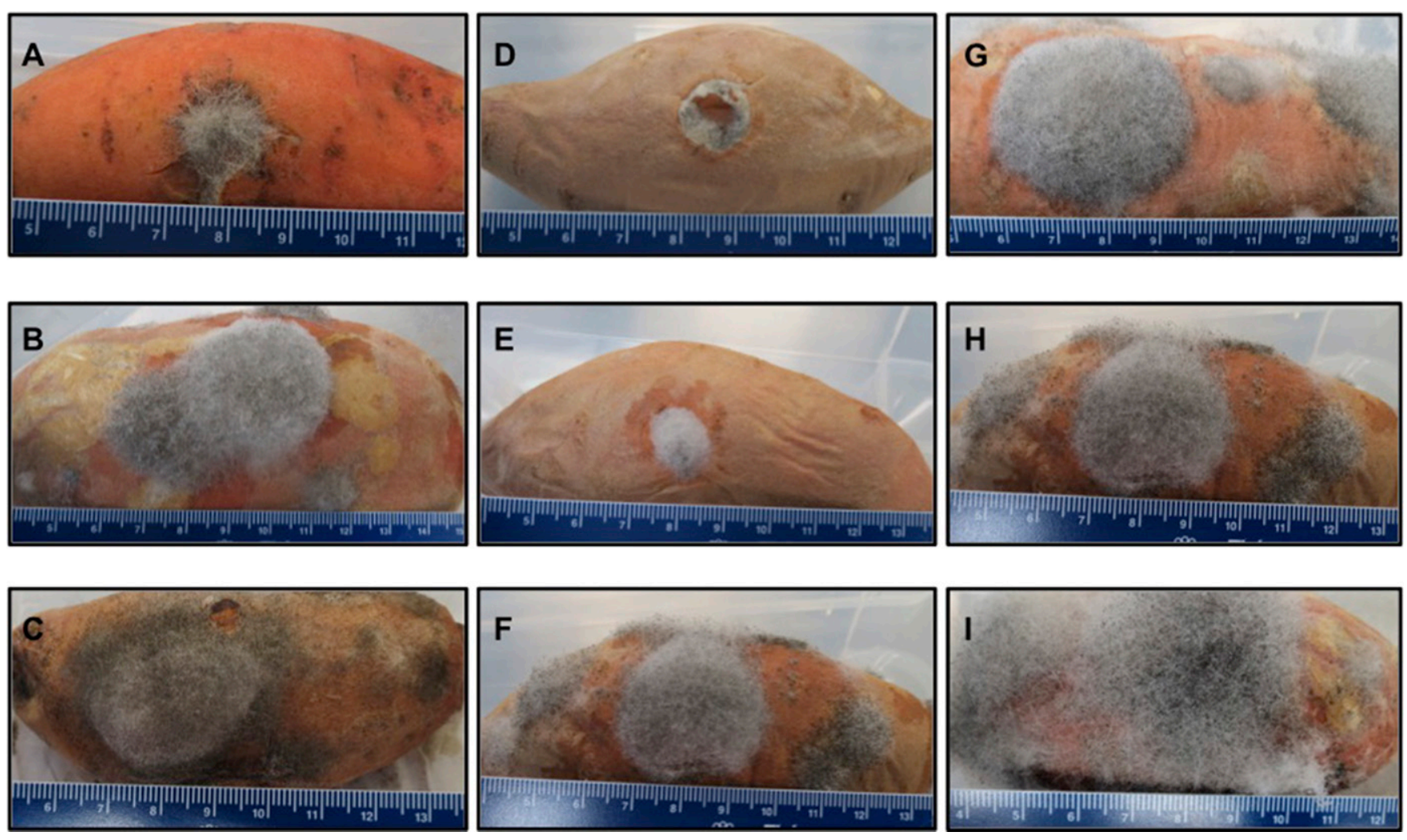

Fig. 2. Symptoms characteristic of Rhizopus soft rot, generated at each tested level of temperature, relative humidity, and initial inoculum level. Soft rot and sporulation typical of Rhizopus stolonifer when stored at A, $13^{\circ} \mathrm{C} ; \mathrm{B}, 23^{\circ} \mathrm{C} ; \mathrm{C}, 29^{\circ} \mathrm{C} ; \mathrm{D}, 80 \%$ humidity; E, $90 \%$ humidity; and $\mathrm{F}, 100 \%$ humidity or inoculated with a G, 3-mm; H, 5-mm; or I, 7-mm mycelial plug. 
Table 3. Effects of temperature, humidity, and inoculum level on progression of Rhizopus soft rot and sporulation of Rhizopus stolonifer

\begin{tabular}{lcc}
\hline & \multicolumn{2}{c}{ AUDPC \pm SE $^{\mathbf{z}}$} \\
\cline { 2 - 3 } Effect & Mean decay & Mean sporulation \\
\hline Temperature $\left({ }^{\circ} \mathrm{C}\right)$ & $92.4 \pm 28.1 \mathrm{a}$ & $101.3 \pm 12.5 \mathrm{a}$ \\
13 & $631.0 \pm 12.4 \mathrm{~b}$ & $250.3 \pm 18.8 \mathrm{~b}$ \\
23 & $746.5 \pm 20.0 \mathrm{c}$ & $255.8 \pm 18.2 \mathrm{~b}$ \\
29 & & \\
Relative humidity $(\%)$ & $590.7 \pm 33.6 \mathrm{a}$ & $116.3 \pm 12.0 \mathrm{a}$ \\
80 & $546.6 \pm 30.0 \mathrm{a}$ & $112.3 \pm 17.7 \mathrm{a}$ \\
90 & $631.0 \pm 12.4 \mathrm{a}$ & $250.3 \pm 18.8 \mathrm{~b}$ \\
100 & $625.4 \pm 18.9 \mathrm{a}$ & $234.6 \pm 27.6 \mathrm{a}$ \\
Inoculum level (mm) & $631.0 \pm 12.4 \mathrm{a}$ & $250.3 \pm 18.8 \mathrm{ab}$ \\
3 & $673.9 \pm 26.7 \mathrm{a}$ & $315.2 \pm 26.5 \mathrm{~b}$ \\
5 & & \\
7 & & \\
z Mean area under disease progress curve (AUDPC) \pm standard error $(\mathrm{SE})$. \\
Means followed by different letters indicate significance between treatment \\
levels within each factor at the 0.05 significance level. Treatments that share \\
a letter are not significantly different.
\end{tabular}

between the 80 and $90 \%$ humidity levels; however, sporulation was significantly increased in roots stored at $100 \%$ humidity (Table 3 ). Sporulation was first observed at $2 \mathrm{dpi}$ at all treatment levels. Sporulation in roots stored at $100 \%$ humidity progressed at a higher rate compared with roots stored at 80 and $90 \%$ humidity, which progressed at a similar rate (Fig. 3D).

Effect of inoculum level on disease development. The effects of initial inoculum level on progression of Rhizopus soft rot and sporulation of $R$. stolonifer was also investigated using different sizes of mycelia plugs for inoculation. Similar to the effects of relative humidity, no significant difference was observed between treatments (3-, 5-, and 7-mm mycelial plug) for disease progression calculated using estimated percent decay (Table 3). Regardless of initial inoculum level, symptoms were observed at a similar time point and progressed at a similar rate (Fig. 3E). However, initial inoculum level did have a significant effect on sporulation of $R$. stolonifer (Table 3). As initial inoculum level increased, sporulation of infected roots also increased (Fig. 3F). Significant differences were observed between sporulation in treatments at low (3-mm mycelial plug) and high (7-mm mycelial plug) inoculum levels. Although sporulation at each of the three treatment levels was observed at the same time and

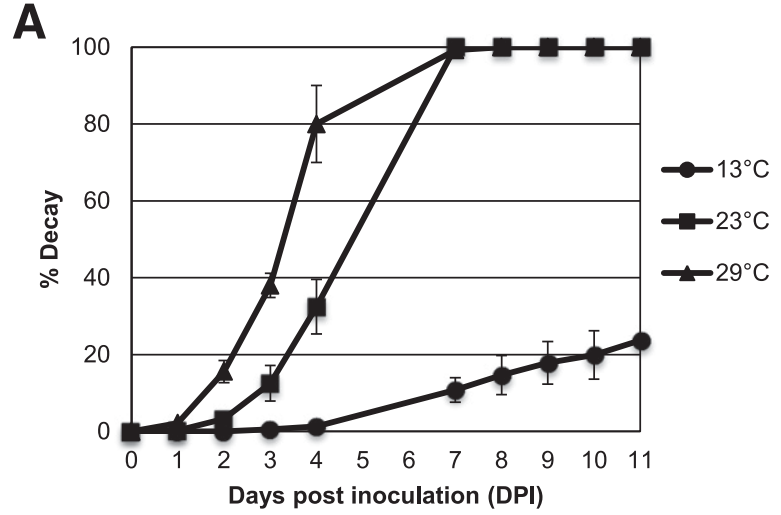

C

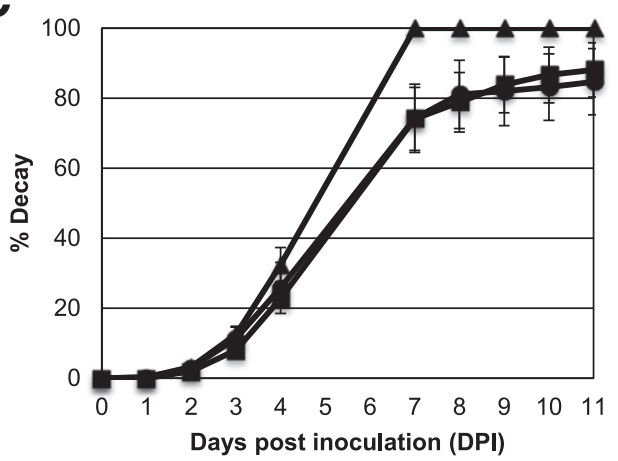

E

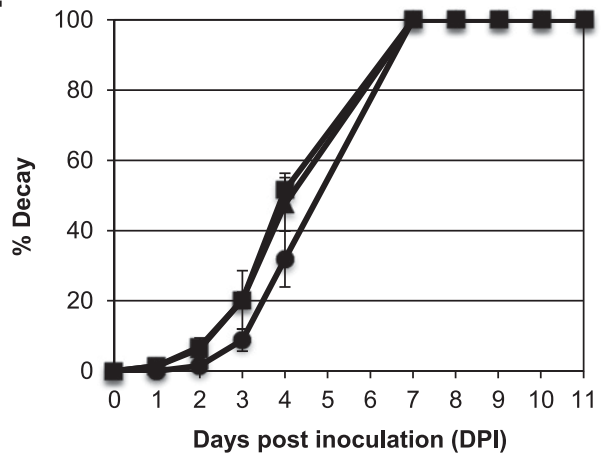

B

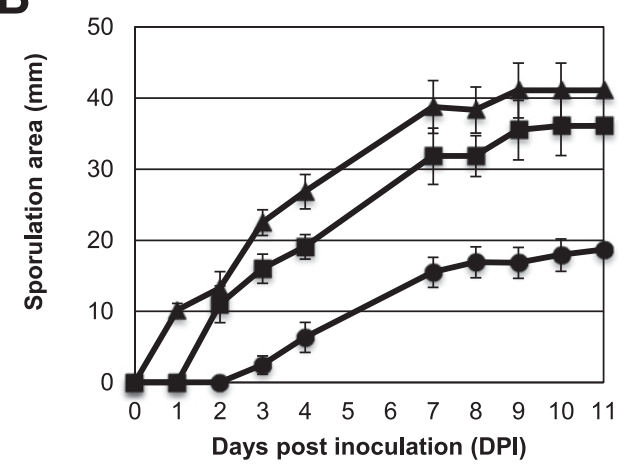

D

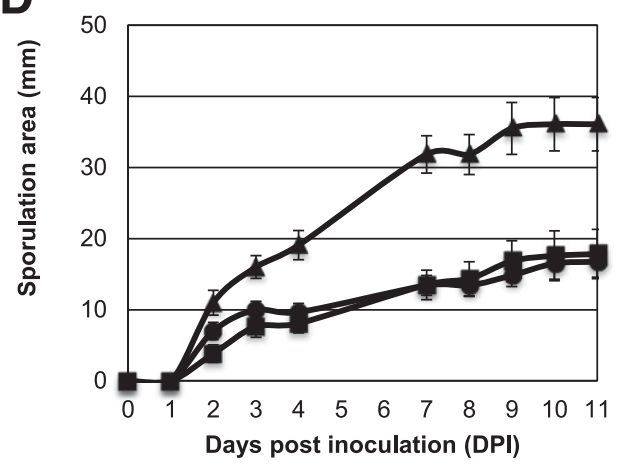

$\mathbf{F}$

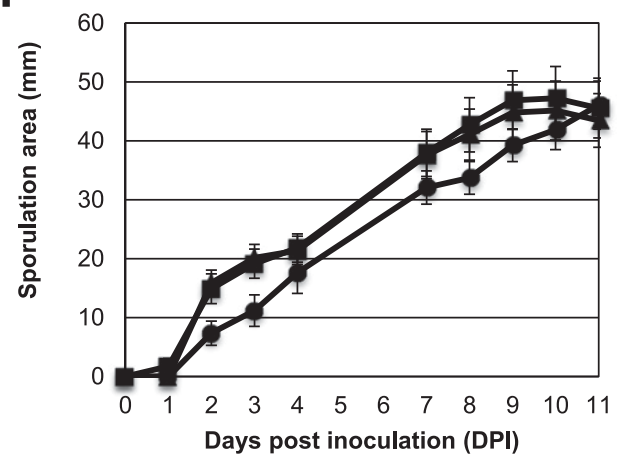

Fig. 3. Progression of Rhizopus soft rot as estimated percent decay over an 11-day observation period as affected by $\mathbf{A}$, temperature; $\mathbf{C}$, relative humidity; and $\mathbf{E}$, initial inoculum level. Sporulation of Rhizopus stolonifer over an 11-day period as affected by B, temperature; $\mathbf{D}$, relative humidity; and $\mathbf{F}$, initial inoculum level. Error bars represent the standard error of the mean. 
progressed at a similar rate, higher initial inoculum levels resulted in a higher level of sporulation when sporulation was first observed (Fig. 3F).

UV-C irradiation experiment. UV-C treatment of sweetpotato roots at varying doses $\left(1.08,3.24\right.$, and $\left.7.56 \mathrm{KJ} / \mathrm{m}^{2}\right)$ either $24 \mathrm{~h}$ before inoculation or $1 \mathrm{~h}$ after inoculation was examined for potential to induce resistance to Rhizopus soft rot or treat Rhizopus spp.-infected roots, respectively. Roots were evaluated 10 days after treatment for disease incidence. A $\chi^{2}$ analysis revealed significant differences between treatments (Table 4). Posthoc multiple comparisons tests showed that treatment of inoculated sweetpotato roots $1 \mathrm{~h}$ after inoculation at $3.24 \mathrm{KJ} / \mathrm{m}^{2}$ was the only treatment significantly different from the inoculated, untreated control. No dose of UV-C irradiation seemed effective at inducing resistance when treated $24 \mathrm{~h}$ prior to inoculation. No UV-C treatments before or after inoculation had any obvious effect on sporulation of diseased roots (data not shown).

$\mathrm{ClO}_{2}$ fumigation. $\mathrm{ClO}_{2}$ gas treatment of inoculated sweetpotato roots was also evaluated in the present study for its effect on Rhizopus soft rot disease incidence and sporulation of $R$. stolonifer in infected roots. A $\chi^{2}$ analysis of static $\mathrm{ClO}_{2}$ treatment of inoculated roots for a 10-day period revealed no significant difference in incidence of Rhizopus soft rot between low and high levels of $\mathrm{ClO}_{2}$ gas and the untreated control. However, significant differences were observed in sporulation of infected roots. The two-dimensional area of fungal growth was calculated using image analysis and subject to an ANOVA, and shows that significant reductions in fungal growth were achieved with $\mathrm{ClO}_{2}$ treatment at both the low and high gas concentrations (Figs. 4 and 5). Active $\mathrm{ClO}_{2}$ fumigation using a fan system developed to simulate treatment of an entire sweetpotato storage room was also investigated for its effect on Rhizopus soft rot. Similarly to the static gas treatments, no significant difference in disease incidence was observed between treated (low and high concentrations)

Table 4. Percent incidence of Rhizopus soft rot 10 days following treatment with $\mathrm{UV}$ irradiation, chlorine dioxide $\left(\mathrm{ClO}_{2}\right)$ fumigation, or dips in alternative control products

\begin{tabular}{lc}
\hline Treatment & Disease incidence $(\%) \pm \mathbf{S E}^{\mathbf{z}}$ \\
\hline $\mathrm{UV}$ irradiation & \\
Uninoculated control & $6.7 \pm 6.7 \mathrm{a}$ \\
Inoculated control & $76.7 \pm 6.7 \mathrm{c}$ \\
$1.08 \mathrm{KJ} / \mathrm{m}^{2}$ before & $73.3 \pm 17.6 \mathrm{c}$ \\
$3.24 \mathrm{KJ} / \mathrm{m}^{2}$ before & $80.0 \pm 0.0 \mathrm{c}$ \\
$7.56 \mathrm{KJ} / \mathrm{m}^{2}$ before & $60.0 \pm 0.0 \mathrm{c}$ \\
$1.08 \mathrm{KJ} / \mathrm{m}^{2}$ after & $66.7 \pm 12.0 \mathrm{c}$ \\
$3.24 \mathrm{KJ} / \mathrm{m}^{2}$ after & $26.7 \pm 12.0 \mathrm{ab}$ \\
$7.56 \mathrm{KJ} / \mathrm{m}^{2}$ after & $53.3 \pm 12.0 \mathrm{bc}$ \\
$\mathrm{ClO} 2$ Fumigation & \\
Static & \\
Uninoculated control & $6.7 \pm 6.7 \mathrm{a}$ \\
Inoculated control & $63.3 \pm 6.7 \mathrm{~b}$ \\
Low ClO & $50.0 \pm 15.3 \mathrm{~b}$ \\
$\mathrm{High} \mathrm{ClO}_{2}$ & $50.0 \pm 17.3 \mathrm{~b}$ \\
Active & \\
Uninoculated control & $0.0 \pm 0.0 \mathrm{a}$ \\
Inoculated control & $66.0 \pm 2.0 \mathrm{bc}$ \\
Low $\mathrm{ClO}_{2}$ & $72.0 \pm 4.0 \mathrm{c}$ \\
High $\mathrm{ClO}_{2}$ & $46.0 \pm 2.0 \mathrm{~b}$ \\
Alternative dips & \\
Uninoculated control & $3.3 \pm 3.3 \mathrm{a}$ \\
Inoculated control & $53.3 \pm 8.8 \mathrm{c}$ \\
Botran $75 \mathrm{WP}$ & $10.0 \pm 5.8 \mathrm{ab}$ \\
$\mathrm{ClO}$ & $13.3 \pm 3.3 \mathrm{ab}$ \\
StorOx 2.0 & $13.3 \pm 6.7 \mathrm{ab}$ \\
Prophyt & $20.0 \pm 5.8 \mathrm{abc}$ \\
Zonix & $40.0 \pm 10.0 \mathrm{bc}$ \\
\hline
\end{tabular}

${ }^{\mathrm{z}}$ Percent disease incidence \pm standard error (SE). Means followed by different letters indicate significance between treatment levels within each factor at the 0.05 significance level. Treatments that share a letter are not significantly different. and untreated roots. Furthermore, there were no differences observed in sporulation level of infected roots in the treated versus untreated sweetpotato (data not shown).

Alternative product dips. Finally, postharvest dips of inoculated sweetpotato roots in alternative liquid products were assessed for control of Rhizopus soft rot. Only 53.3\% disease incidence was observed in the untreated controls but separation of treatments was still observed (Table 4). Dicloran (Botran), included as an industry standard, resulted in the lowest level of disease incidence at $10 \%$, followed by $\mathrm{ClO}_{2}$ solution and peroxyacetic acid + hydrogen peroxide (StorOx $2.0)$ at $13.3 \%$. A $\chi^{2}$ analysis revealed significant differences between the inoculated, untreated control and treatments of dicloran (Botran), $\mathrm{ClO}_{2}$ solution, and peroxyacetic acid + hydrogen peroxide (StorOx 2.0). These treatments were also not significantly different from the uninoculated control. Disease incidence of roots treated with potassium phosphite (Prophyt) or rhamnolipid biosurfactant (Zonix) was not significantly lower than the inoculated, untreated control.

\section{Discussion}

This study demonstrates the ability of $R$. stolonifer to infect Covington sweetpotato roots over a range of temperatures, relative humidities, and initial inoculum levels. Observation of inoculated sweetpotato roots over an 11-day period revealed that storage of roots at $29^{\circ} \mathrm{C}$ was most favorable for disease development and that storage at $13^{\circ} \mathrm{C}$ significantly reduced progression of Rhizopus soft rot in sweetpotato. Although no recent work has examined the effect of storage conditions on Rhizopus soft rot, early work by Lauritzen and Harter (1925) found that growth on culture was greatest at $28^{\circ} \mathrm{C}$ but infection of sweetpotato by $R$. stolonifer was optimal at $20^{\circ} \mathrm{C}$ due to the increased production of pectolytic enzymes required for sweetpotato infection. These findings could vary, however, depending on isolate, inoculation method, or cultivar, as seen in more recent studies (Holmes and Stange 2002). Other reports suggest that $R$. stolonifer causes greater soft rot severity in sweetpotato at temperatures between 6 and $22^{\circ} \mathrm{C}$ (Clark et al. 2013). Differences in the current study likely stem from differences in host physiology, because an alternate cultivar was used and host physiology plays a major role in susceptibility to Rhizopus soft rot, which can also be altered by varying storage conditions (Holmes and Stange 2002; Moline and Lipton 1987). Temperature also had a significant role on sporulation area of $R$. stolonifer in infected sweetpotato in the current study. Abundant sporulation was observed at both 23 and $29^{\circ} \mathrm{C}$; however, sporulation was greatly reduced when roots were stored at $13^{\circ} \mathrm{C}$. These results better align to previous reports of optimum $R$. stolonifer growth at temperatures at or above $20^{\circ} \mathrm{C}$ (Lauritzen and Harter 1925). Long-term storage of sweetpotato roots above the currently recommended storage temperature of $13^{\circ} \mathrm{C}$ can result in a loss of quality due to physiological effects such as pithiness, dry matter loss, sprouting, and shrinkage (Edmunds et al. 2008). Although storage of roots at temperatures lower than $13^{\circ} \mathrm{C}$ may help to further reduce

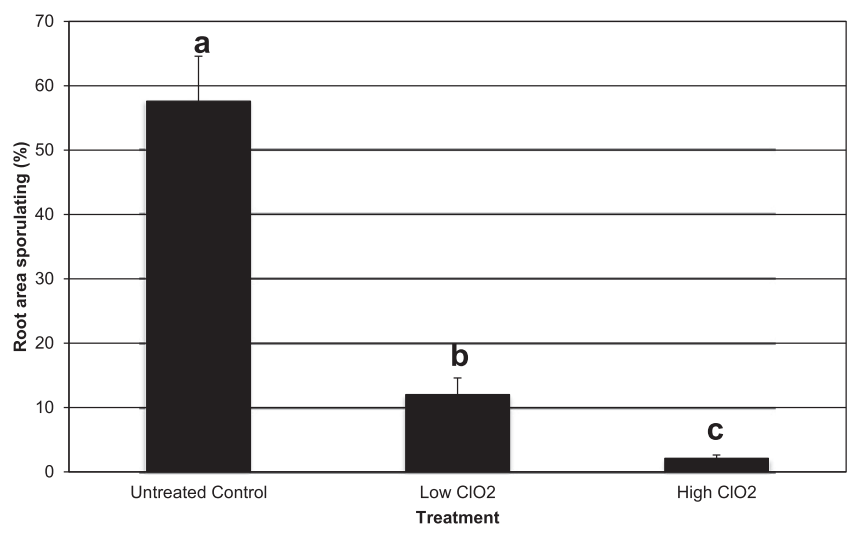

Fig. 4. Effect of low and high concentrations of chlorine dioxide $\left(\mathrm{ClO}_{2}\right)$ fumigation in a static system on sporulation of Rhizopus stolonifer in inoculated sweetpotato after 10 days of continuous exposure. Error bars represent the standard error of the mean. 
Rhizopus soft rot, it is not recommended due to the potential of chilling injury or favorability of other sweetpotato pathogens (Clark et al. 2013).

Investigations into the effects of relative humidity on infection and progression of Rhizopus soft rot of sweetpotato suggests that relative humidities at or above $80 \%$ have little to no effect on progression of soft rot, because there were no significant differences observed between tested treatments of 80, 90, and $100 \%$ humidity. Early reports found that humidities between 75 to $84 \%$ were optimum for the initial stage of Rhizopus infection (Lauritzen and Harter 1926) and that few infections occurred at humidity levels above $93 \%$. In the present study, we were consistently able to reproduce high levels of soft rot at each of the tested humidity levels, including at $100 \%$. Similar results were obtained in a related study investigating the effects of humidity on Rhizopus soft rot of strawberry. In that study, Khalid and Jordon (1976) also determined that relative humidity had little or no effect on infection and progression of Rhizopus soft rot of strawberry. The inability of relative humidity to affect progression of Rhizopus soft rot may be due to the rapid onset of disease upon inoculation and the necrotrophic lifestyle of $R$. stolonifer, because infection results in a watery decay. Although there was no observed effect of relative humidity on disease progression in the present study, there was a significant increase in sporulation for roots stored at $100 \%$ humidity compared with those stored at the lower humidity levels. The impact that relative humidity has on sporulation of $R$. stolonifer has not previously been well assessed. However, relative humidity has been shown to be important in aerial mycelium and conidia production in the necrotrophic fungus Botrytis cinerea (Thomas et al. 1988). In this study, aerial mycelium and conidia production was most abundant and quickest to form at the highest tested humidity level (94\%). Aerial mycelium failed to develop at all at low humidities of $69 \%$ (Thomas et al. 1988), signifying the importance of relative humidity for sporulation development.

In addition to examining the effects of temperature and relative humidity on progression of Rhizopus soft rot and sporulation of $R$. stolonifer, initial inoculum level was also assessed for its potential role in contributing to the disease. Mycelial plugs were used in this study based on preliminary experiments to ensure consistent disease prevalence that was not achieved using spore suspensions. Modifying initial inoculum levels by varying the size of mycelial plugs introduced into artificial wound sites revealed no significant difference in progression of Rhizopus soft rot between inoculum levels. In a previous study, inoculum concentration, modified by using various $R$. stolonifer spore concentrations, did have a significant impact on development of Rhizopus soft rot on tomato fruit (Silveira et al. 2001). Progression of Rhizopus soft rot increased as inoculum concentration increased at inoculum concentrations lower than $10^{4} \mathrm{spores} / \mathrm{ml}$. At inoculum concentrations higher than this level, there was no difference in development of soft rot (Silveira et al. 2001). This evidence suggests that inoculum level may be important in reducing progression of Rhizopus soft rot up until a certain threshold and, once that inoculum threshold is reached, inoculum level is no longer important because potential for disease development is already maximized. It is possible that even the lowest inoculum level used in the present study (3-mm plug) was still too high to see any separation for soft rot progression between treatments. A separate study in sweetpotato examined the influence of varying $R$. stolonifer spore concentrations on percent soft rot using different cultivars and wounding methods (Clark and Hoy 1994). It was shown that percent soft rot was influenced by inoculum concentration for 'Hernandez' and 'T-30-13' when a puncture type wound was used. Inoculum level had no effect on percent soft rot on any cultivar when an impact wound was used or for 'Beauregard' and 'Jewel' using a puncture wound (Clark and Hoy 1994). Covington sweetpotato was not evaluated in this previous study. Based on this evidence, it is possible that we did not see an effect of inoculum level due to our impact-like wound, or that percent soft rot of Covington is not affected by inoculum concentration. However, the effect of inoculum level was significant in the current study for sporulation, because significant differences in sporulation were obtained between the low (3-mm mycelial plug) and high (7-mm mycelial plug) inoculum levels.

UV-C irradiation was tested for its ability to either induce resistance in sweetpotato roots or to successfully treat inoculated sweetpotato roots. Previous reports have investigated the effect of hormetic UV-C treatment to induce resistance in sweetpotato to various postharvest pathogens (Stevens et al. 1997, 1999) and to determine the efficacy of UV to treat field-inoculated roots (Stevens et al. 1990) but, to our knowledge, UV treatment has not been evaluated on Covington sweetpotato, the primary variety grown in North Carolina. The present study found that UV-C treatment at $3.24 \mathrm{~kJ} / \mathrm{m}^{2} 1 \mathrm{~h}$ after inoculation significantly reduced subsequent development of Rhizopus soft rot. Stevens et al. (1997) found that treatment of sweetpotato roots at a dose of $3.6 \mathrm{~kJ} / \mathrm{m}^{2}$ was effective at reducing soft rot incidence in naturally and artificially inoculated roots. UV exposure at similar dosage has also shown to induce resistance to Fusarium root rot (Stevens et al. 1999). Considering that no significant reduction in disease incidence was observed at the $7.56 \mathrm{~kJ} / \mathrm{m}^{2}$ treatment after inoculation, the effect of UV irradiation appears not to be germicidal but is likely a hormetic effect, as previously observed (Stevens et al. 1997). In the current study, UV-C treatment $24 \mathrm{~h}$ prior to artificial inoculation was conducted at various doses to investigate the potential for induced resistance to Rhizopus soft rot. No significant reductions in disease incidence were observed 10 days after treatment in treated and untreated roots. This could be because UV-C treatment is not effective in inducing resistance in Covington to Rhizopus soft rot or that sufficient time was not allowed for resistance induction.

Interest in the use of $\mathrm{ClO}_{2}$ fumigation as a postharvest treatment to control sweetpotato diseases during storage and transport is on the rise. The current study aimed to investigate the efficacy of $\mathrm{ClO}_{2} \mathrm{fu}-$ migation on control of Rhizopus soft rot using two separate gas delivery methods. Previous reports have shown $\mathrm{ClO}_{2}$ fumigation to be effective in controlling bacterial diseases of tomato (Mahovic et al. 2007) and others have shown it to be effective against fungal
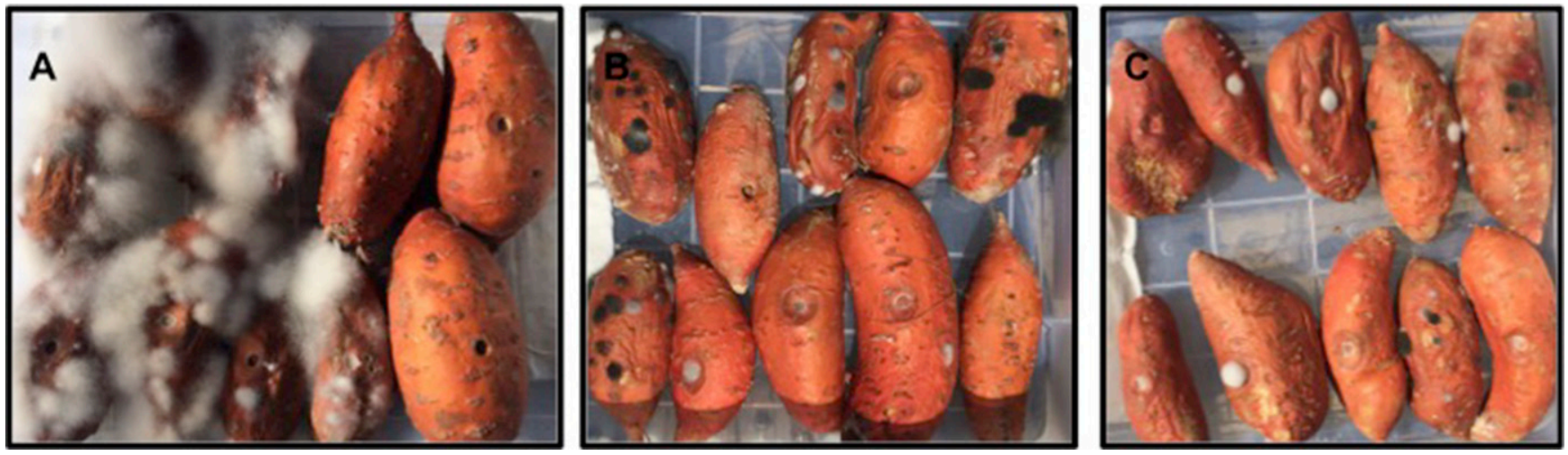

Fig. 5. Observed effect of chlorine dioxide $\left(\mathrm{ClO}_{2}\right)$ fumigation in a static system 10 days after inoculation on decay and sporulation of sweetpotato roots infected with Rhizopus soft rot. Abundant sporulation occurred in $\mathbf{A}$, untreated roots, whereas sporulation was reduced at both the $\mathbf{B}$, low and $\mathbf{C}$, high $\mathrm{ClO}_{2}$ concentrations. 
pathogens of potato such as Fusarium spp. and Helminthosporium solani in vitro (Olsen et al. 2003). To our knowledge, $\mathrm{ClO}_{2}$ gas has not been evaluated for efficacy against Rhizopus soft rot or any other disease in sweetpotato. For the purposes of the present study, two $\mathrm{ClO}_{2}$ delivery methods were tested for disease control that simulate different applications throughout the storage and transport life of a sweetpotato. A static treatment, achieved by placing the gas-producing sachets inside of a sealed box containing inoculated roots, mimicked the commercial method of placing reaction sachets into each sweetpotato box during shipment. An active delivery method, achieved using a fan-delivered system through a column of inoculated sweetpotato roots (Fig. 1), simulated the treatment of entire storage rooms or transport trucks that already have ventilation and air circulation systems in place. The current study found that $\mathrm{ClO}_{2}$ treatment with either delivery system produced no significant reduction in incidence of Rhizopus soft rot when compared with the untreated control. Similarly, studies in potato found no difference in the level of dry rot or silver scurf between treated and untreated tubers (Olsen et al. 2003). However, it was observed in the present study that static treatment of roots with $\mathrm{ClO}_{2}$ gas resulted in significant reductions in sporulation of $R$. stolonifer on infected roots at both the low and high gas concentrations (Figs. 4 and 5). This effect was not observed in roots treated in the active system, suggesting that long, continued exposure to $\mathrm{ClO}_{2}$ gas is required for sporulation reduction. Limited research has evaluated the effect of $\mathrm{ClO}_{2}$ gas on fungal growth; however, Morino et al. (2007) showed that low concentrations of $\mathrm{ClO}_{2}$ gas were effective in reducing hyphal growth of the fungus Alternaria alternata. Although $\mathrm{ClO}_{2}$ does not appear to be effective in controlling Rhizopus soft rot, it is effective in static-type treatments to reduce secondary inoculum production, which may help reduce secondary spread in a commercial setting.

The present study also investigated the efficacy of postharvest dips in aqueous products for control of Rhizopus soft rot. Moderate disease pressure was obtained in the study (53\% disease in untreated control); therefore, the efficacy of these products may differ under higher disease pressure $(>90 \%)$. Under moderate disease pressure, aqueous $\mathrm{ClO}_{2}$ and peroxyacetic acid + hydrogen peroxide (StorOx 2.0) treatments resulted in significantly lower disease levels compared with the untreated control and performed similarly to the industry standard of dicloran (Botran 75WP). Aqueous $\mathrm{ClO}_{2}$ is commonly used as a sanitizer for food safety purposes but its efficacy in controlling Rhizopus soft rot of sweetpotato was previously unknown. Likewise, peroxyacetic acid + hydrogen peroxide (StorOx 2.0) has not previously been tested on sweetpotato but products with similar active ingredients have been shown to not be effective against Rhizopus soft rot (Edmunds and Holmes 2009), although higher levels of disease were obtained in that study. Studies on control of Rhizopus soft rot of pome fruit have shown some efficacy in similar products but suggest that fruit must be dipped for longer periods of time (Mari et al. 2004). To our knowledge, rhamnolipid biosurfactant (Zonix) and potassium phosphite (Prophyt) have not previously been tested for efficacy against Rhizopus soft rot of sweetpotato. In the current study, treatment with these products resulted in disease levels lower than but not significantly different from the untreated control.

The purpose of the current study was to identify potential cultural and alternative strategies to control Rhizopus soft rot of sweetpotato. In summary, $R$. stolonifer is able to infect sweetpotato roots over a wide range of temperature, humidity, and initial inoculum levels. The current study found that storage of roots at $13^{\circ} \mathrm{C}$ resulted in lower disease progression as compared with higher temperatures. Relative humidity levels at or above $80 \%$ do not seem to affect progression of Rhizopus soft rot; however, higher humidity levels $(>95 \%)$ and higher initial inoculum levels can increase sporulation of infected roots, leading to perhaps greater secondary spread. UV irradiation at a certain dose of previously inoculated roots may help reduce subsequent incidence of Rhizopus soft rot. Fumigation of roots with $\mathrm{ClO}_{2}$ gas seems to have no effect on reducing incidence of Rhizopus soft rot; however, static treatments may be effective in reducing secondary inoculum production by hindering pathogen growth and sporulation. Dips in aqueous $\mathrm{ClO}_{2}$ and $\mathrm{StorOx} 2.0$ were effective in reducing Rhizopus soft rot under moderated disease pressure. With this information, proper recommendations to sweetpotato growers as determined in this study can be provided to reduce losses to Rhizopus soft rot by using integrated strategies of storage in proper conditions and utilizing new alternative control measures for the disease.

\section{Acknowledgments}

We thank all the members of the Quesada lab for their valuable help. This work was supported by funds from the Specialty Crop Block Grant Program Award Number 12-25-B-1688 and the North Carolina State University (NCSU) Hatch Project Number NC02418. We thank S. Butler from the NCSU Plant Disease and Insect Clinic for contributing isolates that were used in the study and the numerous sweetpotato farms in North Carolina that allowed us to sample diseased roots and that donated roots for use in this study.

\section{Literature Cited}

Artschwager, E. F., and Starrett, R. C. 1931. Suberization and wound-periderm formation in sweet potato and gladiolus as affected by temperature and relative humidity. J. Agric. Res. 43:353-364.

Bickers, C. 2015. Sweet potatoes: Juice, pet food products could increase market demand. Online publication. Southeast Farm Press. http://southeastfarmpress. com/vegetables/sweet-potatoes-juice-pet-food-products-could-increasemarket-demand

Ceponis, M., and Butterfield, J. 1974. Retail and consumer losses in sweetpotatoes marketed in metropolitan New York. HortScience 9:393-394.

Clark, C. A., Ferrin, D. M., LaBonte, D. R., Picha, D. H., Smith, T. P., and Villordon, A. 2009. Managing Rhizopus soft rot on sweet potatoes. Online publication. La. State Univ. AgCenter. http://www.lsuagcenter.com/portals/ communications/publications/agmag/archive/2009/spring/managing-rhizopussoft-rot-on-sweet-potatoes

Clark, C. A., Ferrin, D. M., Smith, T. P., and Holmes, G. J. 2013. Compendium of Sweetpotato Diseases, Pests, and Disorders. American Phytopathological Society, St. Paul, MN.

Clark, C. A., and Hoy, M. W. 1994. Identification of resistance in sweetpotato to Rhizopus soft rot using two inoculation methods. Plant Dis. 78:1078-1082.

Clark, C. A., and Moyer, J. W. 1988. Compendium of Sweet Potato Diseases. American Phytopathological Society, St. Paul, MN.

Edmunds, B. A., Boyette, M. D., Clark, C. A., Ferrin, D. M., Smith, T. P., and Holmes, G. J. 2008. Postharvest Handling of Sweetpotatoes. North Carolina Cooperative Extension Service, Raleigh.

Edmunds, B. A., and Holmes, G. J. 2009. Evaluation of alternative decay control products for control of postharvest Rhizopus soft rot of sweetpotatoes. Online publication. Plant Health Prog. doi:10.1094/PHP-2009-0206-01-RS.

FAOSTAT. 2009. Statistical Databases. Food and Agriculture Organization of the United Nations, Rome, Italy.

Holmes, G. J., and Stange, R. R. 2002. Influence of wound type and storage duration on susceptibility of sweetpotatoes to Rhizopus soft rot. Plant Dis. 86:345-348.

Johnson, T., Wilson, N., Worosz, M. R., Fields, D., and Bond, J. K. 2015. Commodity highlight: Sweet potatoes. Vegetables and Pulses Outlook: Special Article VGS-355-SA1. Online publication. United States Department of Agriculture Economic Research Service. http://www.ers.usda.gov/media/ 1834605/vgs-355-sa1.pdf

Khalid, A., and Jordon, V. 1976. Effect of temperature and humidity on Rhizopus soft rot of strawberries. Sudan J. Food Sci. Technol. 8:61-67.

Lauritzen, J., and Harter, L. 1926. The relation of humidity to infection of the sweet potato by Rhizopus. J. Agric. Res. 33:527-539.

Lauritzen, J., and Harter, L. L. 1925. The influence of temperature on the infection and decay of sweet potatoes by different species of Rhizopus. J. Agric. Res. 30: 793-810.

Liou, G.-Y., Chen, S.-R., Wei, Y.-H., Lee, F.-L., Fu, H.-M., Yuan, G.-F., and Stalpers, J. A. 2007. Polyphasic approach to the taxonomy of the Rhizopus stolonifer group. Mycol. Res. 111:196-203.

Mahovic, M. J., Tenney, J. D., and Bartz, J. A. 2007. Applications of chlorine dioxide gas for control of bacterial soft rot in tomatoes. Plant Dis. 91:13161320.

Mari, M., Gregori, R., and Donati, I. 2004. Postharvest control of Monilinia laxa and Rhizopus stolonifer in stone fruit by peracetic acid. Postharvest Biol. Technol. 33:319-325.

Moline, H. E., and Lipton, W. J. 1987. Market Diseases of Beets, Chicory, Endive, Escarole, Globe Artichokes, Lettuce, Rhubarb, Spinach, and Sweetpotatoes. United States Department of Agriculture, Beltsville, MD.

Morino, H., Matsubara, A., Fukuda, T., and Shibata, T. 2007. Inhibition of hyphal growth of the fungus Alternaria alternata by chlorine dioxide gas at very low concentrations. Yakugaku Zasshi 127:773-777.

NCDA and CS. 2015. Marketing North Carolina Sweetpotatoes. Federal-State Market News Service, Raleigh, NC.

Nelson, S. C. 2009. Rhizopus Soft Rot of Sweetpotato. University of Hawai'i at Manoa, College of Tropical Agriculture and Human Resources, Cooperative Extension Service, Manoa, HI. 
Ogundero, V. 1988. Pectin esterase production by Rhizopus stolonifer from postharvest soft rots of potato tubers in Nigeria and its activity. Nahrung 32:59-65.

Olsen, N. L., Kleinkopf, G. E., and Woodell, L. K. 2003. Efficacy of chlorine dioxide for disease control on stored potatoes. Am. J. Potato Res. 80:387-395.

R Core Team. 2013. R: A Language and Environment for Statistical Computing. R Foundation for Statistical Computing, Vienna.

Schneider, C. A., Rasband, W. S., and Eliceiri, K. W. 2012. NIH image to ImageJ: 25 years of image analysis. Nat. Methods 9:671-675.

Scott, G. 1992. Sweet potatoes as animal feed in developing countries: Present patterns and future prospects. Pages 13-98 in: Roots, Tubers, Plantains and Bananas in Animal Feeding. FAO, Rome.

Silveira, N., Michereff, S., Mariano, R., Tavares, L., and Maia, L. 2001. Influence of temperature, wetness period and fungal inoculum concentration on incidence of post-harvest tomato fruit rots. Fitopatol. Bras. 26:33-38.

Stevens, C., Khan, V. A., Lu, J. Y., Wilson, C. L., Chalutz, E., Droby, S., Kabwe, M. K., Haung, Z., Adeyeye, O., Pusey, L. P., and Tang, A. Y. A. 1999. Induced resistance of sweetpotato to Fusarium root rot by UV-C hormesis. Crop Prot. $18: 463-470$.
Stevens, C., Khan, V. A., Lu, J. Y., Wilson, C. L., Pusey, P. L., Igwegbe, E. C. K., Kabwe, K., Mafolo, Y., Liu, J., Chalutz, E. and Droby, S. 1997. Integration of ultraviolet (UV-C) light with yeast treatment for control of postharvest storage rots of fruits and vegetables. Biol. Control 10:98-103.

Stevens, C., Khan, V. A., Tang, A. Y., and Lu, J. Y. 1990. The effect of ultraviolet radiation on mold rots and nutrients of stored sweet potatoes. J. Food Prot. 53:223-226.

Tang, B., Pan, H., Tang, W., Zhang, Q., Ding, L., and Zhang, F. 2012. Fermentation and purification of cellulase from a novel strain Rhizopus stolonifer var. reflexus TP-02. Biomass Bioenergy 36:366-372.

Thomas, C., Marois, J., and English, J. 1988. The effects of wind speed, temperature, and relative humidity on development of aerial mycelium and conidia of Botrytis cinerea on grape. Phytopathology 78:260-265.

White, T. J., Bruns, T., Lee, S., and Taylor, J. W. 1990. Amplification and direct sequencing of fungal ribosomal RNA genes for phylogenetics. Pages 315-322 in: PCR Protocols: A Guide to Methods and Applications. M. A. Innis, D. H., Gefland, J. J. Sninsky, and T. J. White, eds. Academic Press, New York.

Woolfe, J. A. 1992. Sweet Potato: An Untapped Food Resource. Cambridge University Press, Cambridge, UK. 